Sign Systems Studies 47(3/4), 2019, 552-589

\title{
The case for a semiotic method in Earth system science: Semantic networks of environmental research
}

\section{Alin Olteanu' ${ }^{1}$, Florian Rabitz², Jurgita Jurkevičiené ${ }^{3}$, Agnè Budžyté ${ }^{4}$}

\begin{abstract}
This paper sets a framework for using semiotics as an analytical method for Earth system science. It illustrates the use of such a method by analysing a dataset consisting of 32,383 abstracts of research articles pertaining to Earth system science, modelled as semantic networks. The analysis allows us to explain the epistemological advantages of this method as originating in the systems thinking common in both Earth system science and semiotics. The purpose of this methodological proposal is that of bringing the recent and critical planetary boundaries framework to the attention of ecosemiotics and biosemiotic criticism, and vice versa. Ecosemiotics is a branch of the biosemiotic modelling theory and is thus grounded in Charles Peirce's schematic semiotics, but also developed in inspiration of Juri Lotman's systemic semiotics. Both of these foundations of ecosemiotics are compatible with the rationale of Earth system science, given the schematism of Peirce's semiotics and Lotman's notion of meaning as an affordance of the biosphere. Far from exhausting the hermeneutic possibilities evoked by the discussed dataset, we argue that such semiotic analysis, made possible by the digital capacity of modelling large amounts of data, reveals new horizons for semiotic analysis, particularly regarding humans' modelling of the environment.
\end{abstract}

Keywords: Anthropocene; semiosphere; network analysis; icon; model

1 University of Tartu/Kaunas University of Technology/Vilnius Gediminas Technical University; Department of Semiotics, Jakobi 2, 51005, Tartu, Estonia; e-mail: alin.olteanu@ut.ee.

2 Research Group Civil Society and Sustainability, Faculty of Social Science, Arts and Humanities, Kaunas University of Technology, Kaunas, Lithuania; e-mail: florian.rabitz@ktu.lt.

3 Research Group Civil Society and Sustainability, Faculty of Social Science, Arts and Humanities, Kaunas University of Technology, Kaunas, Lithuania; e-mail: jurgita.jurkeviciene@ktu.lt.

4 Research Group Civil Society and Sustainability, Faculty of Social Science, Arts and Humanities, Kaunas University of Technology, Kaunas, Lithuania; a.budzyte@ktu.lt. 


\section{Introduction: Graphically representing Earth system science}

We propose a semiotic framework for Earth system science within the broader purpose of sketching the conceptual map of environmental research via semantic network analysis. We illustrate our argument with a semiotic analysis of a broad dataset of article abstracts from top natural science journals (as rated in Web of Science). We claim that, among other schematic modelling methods, semantic network analysis is intrinsically semiotic. We aim to illustrate how the semiotic conceptualization of the resulting model is particularly insightful for interpreting networks. As such, the paper is a contribution to the twofold aim of: (1) developing semiotic modelling theory (e.g., Anderson, Merrell 1991; Sebeok, Danesi 2000; Nöth 2018) as particularly applicable in the epistemology of environmental research; and (2) explaining the state of the art in environmental research as an evolving network of concepts in light of the developed theory. We do not consider environmental research as a paradigm in the Kuhnian sense (Kuhn 1970[1962]), or as a discourse, as is done in much of the humanities and social research aimed to understand scientific theories as language-based constructions (since, for instance, Foucault 2002[1969] and Rorty 1967). Both of these concepts, paradigm and discourse, imply language-centred theories of knowledge in which a system can be understood as coherent in itself, but rendered cross-disciplinarily untranslatable and not necessarily providing evidence. Instead, we explain that the mereological understanding of a corpus of research as a network composed of sub-networks (diagrams) allows for operating on it as an evidence-providing sign or system of signs. Particularly, we explain how Peirce's semiotics serves as an appropriate framework for such research because: (1) it allows for a minute analysis of networks as icons; (2) it endorses a realist theory of knowledge, necessary for environmental awareness (as implied in bio- and ecosemiotics); and (3) it has recently shown fertile applications in digital modelling. Thus, the paper contributes to the emerging area of environmental humanities (Sörlin 2012) by bringing into focus semiotic modelling and digital methods. In light of the network analysis exhibited, we propose Peirce's notion of Universe of Discourse as a possible semiotic contribution to environmental humanities, as a way of bridging the natural scientific concept of the Anthropocene and the discursive concept of the semioshpere.

In this view, the semantic network structure of a corpus of research is understood to provide evidence because schematically structured models can be used as (logical) predicates. Such structures evidence the possible information contained in the corpus. Nodes of the network connected by edges are understood 
as propositions that, by conveying information, make truth-claims (Stjernfelt 2014: 72-75, see also Stjernfelt 2007: 88) and join together in the formation of arguments. From this Peircean perspective, a network is understood as inscribed onto a sheet of assertion (CP 4.397, 4.414), meaning that the representation of a nod or a link is an assertion and that nothing is asserted that is not represented in the network.

While environmental research is specifically appropriate for being conducted in the form of networks, the proposed framework is applicable to many disciplines and large corpora with complex conceptual content. As a semiotic methodology for environmental research, the framework advanced here suits the scope of ecosemiotics (semiotic theory of ecology), thus drawing on biosemiotic theoretical resources for modelling. The network model is particularly relevant because, as Kull (2003: 590-592) explains, biology could open up to semiotic insights and methods with the emergence of ecology as a biological research area. Ecology produced the shift of focus in biology from ladder and tree-like models to web (or network) models. Moreover, this methodology is harmonious with ecosemiotics also because this branch of semiotics developed in the context of the iconic (see Maran, Kull 2014: 42) and, we argue, reflective (or reflexive) turns (i.e. Bourdieu 1990; Archer 1995).

As such an interdisciplinary first attempt, the paper is far from covering all the possibilities that semiotic modelling theory presents for environmental humanities or for Earth system science. Nevertheless, a starting point for such a framework is proposed. Also, the collected and modelled data should serve to facilitate future investigations in this direction.

\section{Semantic network models of the Earth system}

Our dataset consists of 32,383 abstracts published between 1990 and 2018 in seven top-ranked journals belonging to the Web of Science 'global and planetary change' category. This dataset thus captures a broad range of Earth system research, as per the understanding of Rockström et al. (2009) and Steffen et al. (2015), spanning oceanography, atmospheric chemistry and geology.

We interpret semantic networks as constituting diagrams (specific icons) of state-of-the-art environmental research. As constituting diagrams of a larger discourse, these networks contain information about the larger discourse and can thus be used as iconic models of it. Topic modelling via Latent Dirichlet Allocation enables the identification of distinct themes, or "topics", across a wide range of documents. By assigning individual topics to broader categories associated with 
global environmental change processes, specifically the nine planetary boundaries identified by Rockström et al. (2009), our ongoing work suggests that the thematic weights in the environmental governance literature have shifted over time. The scientific discourse is dominated by topics associated with biosphere integrity (i.e., biodiversity loss and genetic erosion) and climate change, with the latter crowding out the former over time. Simultaneously, other planetary boundaries are either marginalized in the scientific discourse (i.e. chemical pollution as well as the global nitrogen- and phosphorus cycles) or even absent (i.e. ozone depletion and ocean acidification). This suggests two things. First, it illustrates how text mining techniques can be used to pinpoint changes in the structure of scientific research. Second, this structure is heavily biased. This highlights the need for a reflexive approach in order to uphold the diversity of scientific research against bias that may emerge from within the academic debate itself, as well as from exogenous factors related to contemporary scientific practice.

We consider individual semantic networks of Earth system science to belong to the greater picture of the evolution of environmental research over time in the biosemiotic view that knowledge is "a kind of becoming" (Hoffmeyer 2018: 4; for a semiotic concept of becoming see also Stables 2012). Also, from the biosemiotic perspective, knowledge is embodied, meaning that, like knowledge, biological entities are "points on a development trajectory" (Hoffmeyer 2018: 4). Put briefly, biosemiotics studies "the dynamics of semiosis at multiple time scales, and emphasizes the active role organisms have in reshaping sign relations" (Sharov, Maran, Tønnessen 2015: 361). Hence, since the environment, as subjectively related to the body, is the first model that the body organizes, we argue that environmental research, perhaps even more than other areas of scientific inquiry, has to be understood in analogy to embodied structures, in both time and space (or in spacetime). Peirce's rationale of logical representation is that since logic is spatial, logic operations are best represented graphically (Bellucci 2013; Stjernfelt 2015b: 38).

If modelling, as per Sebeok and Danesis (2000: 1) understanding, "is the innate ability to produce forms to stand for objects, events, feelings, actions, situations and ideas perceived to have some meaning, purpose, or useful function", then any further modelling superstructure, scientific, artistic, technological or otherwise, must build upon the primary modelling of the environment. This does not mean that scientific theories should not challenge our folkloric thinking, but that science cannot be abstracted away from our models of the environment. A network structure immediately does this for the human body: we easily understand the relations it depicts. An individual network on its own does not convey much, but in the greater context (or, in Peircean terminology, Universe of Discourse, CP 
3.174; more on it below) of environmental research as proceeding in time it can explain a multitude of dynamics. More so, schemata (as understood in cognitive sciences, e.g., Georgeon, Ritter 2012), particularly image schemata (Johnson 1987; Lakoff 1987), such as networks, can be much more easily coupled together in the bigger puzzle than linear, linguistic explications which suppose a large stratum of convention.

The data document is modelled as consisting of different categories corresponding to planetary boundaries as thresholds that "define the safe operating space for humanity with respect to the Earth system and are associated with the planet's biophysical subsystems or processes" (Rockström et al. 2009: 472; see also Steffen et al. 2015).

The present paper takes semantic network models of Earth system science research as constituting diagrams of environmental research in general. This means that the models analysed are (1) sub-networks of a greater network of environmental research, which (2) they signify by means of inner structural resemblance. In other words, environmental research is the Universe of Discourse (CP 2.373) that the analysed diagrams evoke. We approach the semantic network of key concepts of this corpus as a (semiotic) model, as particularly revealed in networks by term-frequency/inverse-document frequency value.

Term frequency-inverse document frequency (henceforth, tf-idf) is a metric that represents the relative importance of a given word for a given corpus. The assumption behind this metric, characteristic of mereological methods, is that important words will appear frequently within a given document (term frequency) but rarely across the entire corpus (inverse document frequency). The latter ensures that stop words (such as 'the', 'but' or 'that') as well as common words with low semantic content (such as 'research', 'literature' or 'review') are filtered out. By drawing on an initial list of the 500 words with the highest tf-idf scores, we thus isolate words that are semantically meaningful in a systematic manner. We use those terms for generating the edgelist (dyadic relations between nodes/ terms). The weight of the edges between two given terms is equal to the number of abstracts in which they co-occur, divided by the total number of abstracts in the data set. Accordingly, edge weights assume values between 0 and 1 . An edge weight of 1 thus represents a (hypothetical) situation in which a given word pair appears jointly in every single abstract in the data set. For a weight of 0.5 , cooccurrence would appear in every second abstract, and so forth. The edge weight can be said to reveal comparative levels of iconicity within the corpus (more below).

Semantic networks for each year during the studied period were generated by taking the following steps. To eliminate noise from the data to be modelled, the 
32,383 abstracts were pre-processed by lower-casing, the removal of stopwords, punctuation, numbers, words shorter than three characters, by stemming (e.g., words in the corpus such as 'climate' and 'climatic' are reduced to 'climat ${ }^{*}$ ) and white space stripping. After this preparation of the document, the tf-idf was calculated.

Network nodes represent the top 500 tf-idf terms. Edge weights were generated through co-occurrence, normalized to values between 0 and 1 , hence showing the strength of relations between each two nodes. We calculated the following measurements: weighted degree centrality (representing the number of edges as well as their respective weights for a given node, see Opsahl, Agneessens, Skvoretz 2010); weighted betweenness centrality (the extent to which a given node lies on the shortest paths connecting all other nodes in the network); graph-level centralization (i.e. how centralized the entire network is based on the degree centrality and the betweenness centrality of individual nodes); as well as network community structure via the Louvain method (for identifying clusters of nodes that are more tightly connected with each other than they are with the rest of the network). We note that changes in graph-level centralization over time are driven both by changes in the centrality scores of individual nodes as well as in changes to the number of nodes in the network. While we generated the nodes from the top $500 \mathrm{tf}$-idf terms in the entire data set, not every single one of those terms is mentioned in every single year under consideration, thus leading to fluctuations in network size over time

While node centrality measures the "importance" of the individual nodes within a network, centralization measures the extent to which a network is dominated by one, or a few, individual nodes. This allows for observing the centre-periphery dynamics of the network. Following Lotman (1990: 124-130; see Andrews 2003: 33), while the centre of a system contains the language proper of the system, the periphery contains not notions from the system, but ideas challenging the central mainstream. In this view, the centre-periphery asymmetrical structures of the networks in question show what concepts have come to dominate the academic debates in environmental research, and also provide hypotheses about future trends: what can challenge the status quo of such research are the concepts now positioned in the periphery. For our purposes, we use the most basic centrality and centralization metrics that are based on the node degree (the direct connections which a node possesses with other nodes). Because the network is weighted, we adopt the approach proposed by Opsahl, Agneessens, and Skvoretz (2010) which generalizes degree centrality/centralization from unweighted to weighted networks. They propose a "tuning parameter" that allows the analysis either to emphasize the overall number of edges which a node 
possesses, or the total weight of those edges. Here, we choose the latter. That is, we calculate centrality and centralization based on the total "strength" of edges rather than their amount. This has a specific methodological reason. In our analysis, edge weights represent co-occurrence between words (nodes). The weight of an edge $i-j$ is equal to the number of abstracts in our dataset that include the words $i$ and $j$ (we normalize this number to values between 0 and 1). For most of the possible pairs of words included in our network, there is at least one abstract that contains both. In other words, the network is extremely dense, as almost all words/ nodes are directly connected to each other. In this situation, looking at the number of edges that a given node possesses is practically meaningless, especially in a semiotic concern of asymmetry structure. By instead calculating centrality and centralization based on the weights of those edges, we get a clear picture of which words are central within the semantic network, and of how the centralization of the entire network changes over time.

In network analysis communities are understood as a matter of structural position (see, e.g., Fortunato 2009: 77) expressed by the particularly strong connection (high weight values) among groups of nodes in comparison to the rest of a given network. For our purpose, we understand communities as clusters of co-occurring words. Such co-occurrence suggests that the words in a given community form a common repertoire that reflects the linguistic practice of a research community or denote a set of empirical phenomena that are believed to be in a causal relationship of one form or the other. Community detection in complex networks is subject to a great deal of uncertainty. Usually, no ground truth can be established against which to benchmark the performance of different community detection algorithms. Different algorithms yield different results, yet there are a few "hard" criteria for algorithm selection. For our purposes, our choice set is restricted to algorithms that are able to analyse weighted, undirected networks. Following Yang, Algesheimer and Essone (2016), we use the Louvain method for community detection. This is a bottom-up method for optimizing network modularity (the difference between the edges existing in a given group of nodes, and the edges we would expect under a random distribution) that starts at the level of individual nodes and then aggregates upwards until a network partition is found that cannot further be optimized.

Figures 1, 2, 3 and 45 in Supplementary Material, are the visual representations of the semantic network graphs of the analysed dataset for the years 1990, 2000,

5 We mention that node colours designate community membership in a given year. They are a mere visualization aid and the use of the same colour across years does not refer to the continuity of certain communities. 
2010 and 2017 (for a clear visualization, we do not illustrate edge weights with a value below 0.05). Different colours in the graph indicate different semantic communities (though colours across graphs are not related).

We removed the names of nodes (labels), as they would be unreadable in this format. For the specific positioning of each node, we recommend checking the table containing the data in analytical form, comprehensive of edge list and all calculated metrics. Both this table and the networks with labelled nodes are available in the Supplementary Material. The different colours in the networks represent different semantic categories. The differences in shape and size (number of nodes, weight of edges) of the networks illustrate the evolution path of environmental research.

\section{Semiotics as methodological framework for Earth system science: representing the environment}

While the semiotic theory of ecology, which is now well-established, is grounded in nonverbal modelling systems, it has not yet been employed in complementarity to semantic network analysis. Also, despite this method's affinity to semiotic modelling, so far it has not been considered in such a framework. Moreover, while bio- and eco-semiotics have been discussed as valuable methods (or even epistemologies) for ecocriticism (Maran 2010, 2014a, 2014b), and for literary criticism in general, such approaches remain qualitative in the traditional humanist sense. However, one of the main theorists in this area, Timo Maran (2014a, 2014b), explains that the purpose of biosemiotic criticism consists in overcoming the limitations of traditional literary approaches, given the relativist claims these bring. This is, arguably, a characteristic of the reflective turn (see above in Section 1; Bourdieu 1990; Archer 1995), as seen in the social sciences, whereby scientific practice is becoming itself the object of scientific inquiry. This further justifies adopting digital methods for semiotic research.

Nevertheless, while semantic network analysis and semiotic modelling theory appear to be natural allies, particularly as regards systems theory and ecology, the very different terminology involved in each of these makes their bringing together a lofty epistemological and methodological work, which this paper cannot hope to resolve fully. Also, since various elements of linguistics underpin the theory behind semantic networks and the relativist variations of semiotics (e.g. discursive theory), much scrutiny is needed in removing unwanted relativist assumptions in a joined framework. 


\subsection{Limitations of classic literary criticism and digital opportunities}

While insightful in its own right, it is particularly in approaches to environmental matters that the relativist tradition of literary criticism is challenged (see Bishop et al. 2000; Stables, Bishop 2001), because it implies an all too anthropic conceptualization of the environment as text. Our claim is that this perspective results in models of the environment that subdue nature to the symbolism of (modern) human cultures, bending physical constraints to fit (Romantic) ideals about humans' place in the world. As such, our proposed graphic modelling of, and semiotic view on, environmental research will help bridge popular and scientific understandings of the environment. As any model supposes a mediality, we emphasize the advantages of graphic networks as comprising a visual and analytic cross-modality, as aligned with Peirce's system of graphic representations of logical operations (CP 4.561).

The dominant school of text semiotics in the 20th century, supported by (post)structuralism and the mainstream schools of text analysis (e.g., Halliday 2002) employed as representation theories (e.g., Hall et al. 1980), tends to refrain from inferring on the relation between representation and represented object. Inspired by de Saussure's (1959[1916]) semiologie and, subsequently, Martinet's (1962) phonological theory, the relation between form and content is seen as essentially arbitrary in this broad framework of theories. From this point of view, nothing, not even the natural environment, can be understood otherwise than a product of cultural fabrication, subject to culture- and language-specific text representation mechanisms. It is a typical feature of (late) modernism to regard human development as based on conventions. This implies a search for conventions (complex symbols) as the ground for cooperation and innovation. Such conventionalism results in epistemological relativism: differences between human societies are accounted for as based on different conventional systems, the assimilation of which makes for untranslatable cultures and paradigms. As particularly noticed in recent semiotic research, this relativist view implies various problems for, among others, cultural studies (Cobley 2016), multiculturalism (Eriksen, Stjernfelt 2012) and education (Stables 2006; Olteanu 2015). As concerns environmental research, convention-based development often proves unsustainable because it is anthropocentric. In general, 20th-century languagecentrism supposed that culture is mirrored by language and that language-culture dynamics models the reality of humans (see Randviir, Cobley 2010). Recently, Marrone revealingly synthetized text semiotics as a dominating and thoroughly culture- and language-relativist epistemology: 
The text is therefore the specific object of study for the semiotician [...]. The text is not a given entity, nor phenomenal evidence; it is the result of a double construction: a socio-cultural configuration before and an analytic reconfiguration afterwards. The text, in this perspective, is necessarily negotiated within cultural dynamics that, in creating it, come into existence and interlace in an unending chain with other texts, other matters, other languages. The text is not closed in itself but easily remodelled and configured in other textual forms, easily translated into other languages in the never-ending inter-textual, inter-discursive chain of the semiosphere. (Marrone 2017: 108)

This linguistic solipsism is, as a limit case, challenged by the current environmental crisis (as some of us have argued before, also from a semiotic perspective, see Olteanu in Stables et al. 2018: 104). Here, we employ the bio- and eco-semiotic framework(s) for ecocriticism to look at a text (or model) comprising of a large amount of data of complex theoretical content. The point in biosemiotic criticism is that text does not represent the environment in a singular way, but rather, as a hologram represents its object, text can represent an aspect of the environment in its multimodal complexity. Thus, as arguably typical of recent digital humanities research, the present analysis is relevant jointly in a qualitative as well as a quantitative manner. It offers an understanding of the meaning phenomena stemming from how a large amount of concepts structure together in a network. Moreover, by adopting this perspective, we argue that the network contains claims about its represented object, which, in this case, is the state of the art of Earth system science and, further on, it illustrates the state of the environment itself. This interpretation, which has recently become possible due to the capacity of digital technological devices to model large amounts of data, finds support in semiotic modelling theory.

The suggestion thus arises that in an age of globalization and environmental crisis, environmental dynamics can be fully understood only as digitalized: other existing media seem unable to represent the environment in its complexity, in a conclusive way. A critical advantage for modelling of computing is that it simultaneously offers analytic and schematic (diagrammatic) representations of the same object. Particularly from the point of view of systems thinking (Lotman 1990: 13-19; see also Pajević 2014), from the translation between (these) two different types of models, new interpretative possibilities arise. Arguably, broadcasting media did not manage to dismiss climate change skepticism convincingly. Also, their many benefits, such as enhancing activism and civil participation in political debates, aside, recent digital social media seem to have created fertile platforms for science skepticism (see Stuart 2011). This confirms Marrone's position: the text constituting environmental research does not provide any phenomenal evidence. 
However, we claim that it does not provide phenomenal evidence only to a public who cannot be required to practise their civic duties in acknowledgement of cutting-edge scientific theories and their dissemination, or lack thereof, at the dawn of the digital era. It would be impossible for a majority of citizens to have expert knowledge of environmental science.

Thus, we argue for the need of developing ways in which digital modelling can illustrate scientific theories in simple models, accessible at a general level of (environmental and digital) literacy. For this reason, we argue for the importance of expressing environmental research in image schemata, so as to produce texts adequate for a digital literacy that can further cultivate environmental literacy. As such, environmental research has to be represented in media other than the medium of linear language. Thus, the modelling of this corpus into semantic networks is a cross-modal translation, termed transduction, which is "itself transformative" (Kress, Leeuwen 2001: 51), and a transmedial adaptation. In such a process, the media characteristics of the source corpus have to be, to a certain level, preserved in the target media. The purpose is that of achieving a richer variety of media for the interpretation of environmental research. Elleström (2017: 682) explains that:

Hermeneutics can never be escaped. When finding traces of other media in media, whether they are specific media products or qualified media, it sometimes simply makes sense to say that some media should be treated as source media because they are recognizable in other media, which may then be treated as target media. Ultimately, theoretical analysis is nothing without interpretation.

Network modelling is a methodology that environmental research can employ for this purpose. Both the faithfulness to the source corpus and the creativity that it inspires depend on the preservation of iconic relations across media. Digital computation does not perform the translation or interpretation for its interpreter. That would be an exaggerated optimism as concerns digital technology and information theory, of which many (e.g., Eco 1976: 20-21; Pajević 2014: 7; Kull 1998b: 93, 102; 2009: 83; 2018: 457, see also Pikkarianen 2018: 445) are skeptical. Rather, it offers to the interpreter an eligible model, for the interpreter's own apprehension of it. As Hoffmeyer (2008: 4) puts it, "knowledge is never just there, rather we make it up, every time we have a task at hand". Thus, as long as the digitalized model does not lie (convey information which is absent in or contradicted by the source corpus), there should not be any hesitation to model complex corpora. While first aiming to offer a better understanding of the epistemology of environmental research, the present paper also aims to take a step 
in the direction of making scientific knowledge about the environment accessible more broadly.

\subsection{Biosemiotic modelling and systems thinking}

The alternative representation theory to text semiotics (and, generally, textcentred literary theories) proposed here, is a modelling-centred theory. To begin with, biosemiotics is conceived as a semiotic modelling theory. Such an approach is inherent in systems science (or systems thinking), as applied in Earth system science, but an exploration of the latter's affinity to semiotic modelling theory (or theories) is lacking. Thomas Sebeok (e.g., 1991, 2001[1994]) initiated his project of biosemiotics by discovering the compatibility between Jakob von Uexküll's (1926, 2010[1934, 1940]) theoretical biology and Charles Peirce's semiotics. Sebeok (1991: 57) argued that:

Every mental model is [...] a sign; and not only is modeling an indispensable characteristic of the human world, but also it permeates the entire organic world, where, indeed, it developed.

Thus, to begin with, this joining of biology and semiotics implies a phenomenological representation theory based on organism-environment dynamics. It is compatible with the idea in cognitive sciences (see Section 2 above), foundational for cognitive semiotics (e.g., Brandt 2011) that meaning is embodied. Sebeok brought Uexküll's concept of the environment (umwelt) as model (see Uexküll 1982: 87) in the scope of semiotic analysis, in light of Peirce's sign typology (Sebeok 1991, 2001[1994]). Uexküll (1926: 155-156) considered that organisms make sense of their environment(s) through loops of perception-signs and actionsigns. Thus, the environment of an organism is populated by meaning carriers, which the organism has the competences to perceive and can choose to invest with meaning tones (Uexküll 2010[1934, 1940]: 150). For instance, Uexküll (2010[1934, 1940]: 140) explains how, for a human, a stone can have a path tone if it is part of a road, or a weapon tone if the human decides to throw it towards a threatening animal.

As for Sebeok's other main source, Peirce's semiotics proves to be of central importance for the recent iconic turn (Stjernfelt 2007), namely the shift in representation theories from linearly analytic language to schematic forms of representation (regarding the iconic turn see Boehm, Mitchell 2009), such as employed in the present paper, which inspired the development of ecosemiotics (Maran and Kull 2014, see above in Section 1). To begin with, Peirce's semiotics is highly relevant for network analysis because it assumes that only iconic signs 
(such as networks and substructures of networks are) can be used to form predicates (CP 2.278).

The central role that schematic signification (icons and, particularly, diagrams) has in Peirce renders his semiotics as a form of systems thinking, as it offers a view of systems as webs of signs (or graphs). Peirce's concept of system is his notion of Universe of Discourse (CP 3.174), which is determined by the implicit indexicality of propositions (CP 2.372, CP 2.383). Thus, the propositional structures of a network, consisting in nodes connected by edges evoke the general scientific understanding of the environment as Universe of Discourse. Unlike a paradigm (and, arguably, unlike some interpretations of the semiosphere), the notion of Universe of Discourse does not imply a holism of the semiotic space in question, where the evolution and possibilities of individual nodes and (semantic) communities are determined by the whole structure. Rather, it supports a mereological perspective, according to which individual nodes and identifiable communities have a considerable degree of relative independence. Nodes and their interrelations are not bestowed with meaning by a top-down imposition of rules from an overarching paradigm (or semiosphere). Rather, they signify by their compositionality and give rise to the greater semiotic system to which they belong.

In this view, it is acceptable to suppose that research on particular, possibly peripheral topics can be successful and become a central part of the Universe of Discourse. Particularly relevant for environmental research, Peirce's pragmatism endorses a "scientific realism" based on the ability of propositions "to involve the large array of iconic predicate possibilities of maps, diagrams, graphs, etc." (Stjernfelt 2014: 75). Moreover, Peirce's sign typology implies a theory of facts as "states-of-things", which have the Subject-Predicate structure of a proposition (EPII 304). This goes against a main assumption of the linguistic turn, namely that some structures of knowledge are only conceivable in linguistic form. Rather, in agreement with Uexküll's notion of meaning carrier, Peirce considered that semiotic (meaningful) structures are present in the environment, available for organisms to discover and use. Among these, propositions (Subject-Predicate structures), have a pivotal role in the taxonomy of signs, as they convey information by making claims (e.g., the perceived fact of a bird sitting on a branch is a proposition regardless of its linguistic expression, which would be 'Bird sits on branch'). The language of humans, made possible by the accidental physiological possibility of phonetic articulation (Gould, Vrba 1982; see also MacLarnon 2012), proved to be particularly efficient for communicating propositions. However, (human, verbal) language is not the only semiotic competence that makes it possible to identify Subject-Predicate structures in the environment and to 
communicate them. That modelling starts prior to linguistic formalization is one of the starting points for Sebeok's biosemiotics (Sebeok 1991: 56), being also a founding assumption in Peirce's propositional logic (Stjernfelt 2014). Thus, a semantic network of theoretical concepts is understood to make claims in the form of propositions, or dicisigns, as per Peirce's generic term for propositional signs (CP 2.309-2.310), that use relational structures of the network (edges and combinations of edges) as predicates. As such, Peirce's theory of propositions can be used as a tool for extracting truth-claims (see Stjernfelt 2014: 72-75) from network structures, particularly for the scope of environmental research.

It appears that a critical aspect of biosemiotics that recommends it as a framework for Earth system science in particular consists in the overlap of these two. Another source of inspiration for Sebeok's biosemiotics is Juri Lotman's theory of culture as semiotic modelling. Sebeok adopted Lotman's concept of model as "a structure of elements and of rules for combining them that is in a state of fixed analogy to the entire sphere of an object of knowledge, insight or regulation" (Lotman 1977: 7). Further, Lotman considered that "a modeling system can be regarded as a language. Systems that have a natural language as their basis and that acquire supplementary superstructures, thus creating languages of a second level, can appropriately be called secondary modeling systems" (Lotman 1977: 7). Sebeok agreed with the idea that, for humans, natural languages are modelling systems that open up the possibility for new layers of modelling systems such as culture, art, science and technology. However, he also made a critical addition to Lotman's idea by claiming that much modelling of living organisms, including humans, is nonverbal (hence, pre-linguistic), in view of the 'language as exaptation' hypothesis (Gould, Vrba 1982). Thus, he employed the Uexküllian concept of Innenwelt to denote this primary, pre-linguistic modelling system, in which language and all modelling superstructures are rooted (Sebeok 2001[1994]: 145):

The Innenwelt of every animal comprises a model [...] that is made up of an elementary array of several types of nonverbal signs [...].

These nonverbal signs are schematic in a way relative to the animal's morphology and physiology. This accounts for the self-explanatory insight that diagrams, such as networks, have for an animal, once the animal chooses to use the respective diagram in its modelling of the environment. 


\subsection{Semiosphere and Anthropocene}

While Lotman's modelling theory appears language-centred at times, both systems thinking and biocentrism still have their place in his semiotics - an argument supported also by Hartley (2015: 85), who is thus led to adopt Lotman's semiotics to develop a scholarly framework for creative cities as networks of particular structure. To begin with, Lotman discussed cultural phenomena in view of modelling systems, where a system consists in, loosely speaking, a structured composition of signs. This is probably a direct Peircean influence on Lotman. According to Andrews (2003: xv; Andrews in Lotman 2009: xxii-xxiii), Lotman also preferred Peirce's semiotics to the Saussurean brand, albeit via Umberto Eco's early reading of Peirce (Eco 1976) and the latter's reception, in general, in poststructuralism, and despite Lotman's reliance on Saussurean semioticians such as Hjelmslev (e.g., Andrews in Lotman 2009: xx; Torop in Lotman 2009: xxviii). It has been a central aspect of the Tartu-Moscow School of Semiotics, of which Lotman is emblematic, that "a scientific metasystem may describe culture" (Andrews 2003: 10). Culture and communication, according to Lotman, are possible only within what he termed 'semiosphere' (a concept on which, according to Marrone, text semiotics also relies, see Section 3.1 above), and which he defined as "the semiotic space necessary for the existence and functioning of languages" (Lotman 1990: 123). For a proper understanding of the semiosphere and, hence, of Lotman's theory of modelling, this definition has to be taken as an addition to the concept of biosphere, which Lotman inherited from Vernadsky (see Maran 2014b).

According to Vernadsky (2005[1943]: 17), the biosphere is the geological "envelope of the Earth, which is the only place where life can exist". This concept is of interest because humankind, as well as any other biological species, is "inseparably connected with the material-energetic processes" of the biosphere (Vernadsky 2005[1943]: 17). Vernadsky was interested in how humankind changes the biosphere into a different geological formation, one attuned to the mind of humans, which he termed noösphere. Lotman, in a semiotic and, arguably even less dualist manner, was inspired by Vernadsky to conceive of a semiosphere: a biosphere shaped by the cultures of living beings. Recently, semiotic research seems to have been displaying a renewed interest in the mutual relation between meaning and landscape (Lavrenova 2019; Wee, Goh 2020), which also suggests an impact of environmental humanities here as well. Lotman's semiotic modelling theory contains the systems thinking notions to address the more recent concept of the Anthropocene (Crutzen, Stoermer 2000), which guides environmental humanities research. Arguably, the human semiosphere is an avant-garde notion 
of the Anthropocene. Crutzen (2006: 13) mentions Vernadsky as a precursor of the Anthropocene concept, together with George P. Marsh, Antonio Stoppani, Teilhard de Chardin and Edouard Le Roy. It is particularly Vernadsky, de Chardin and Le Roy's concept of 'noösphere' that appears to be closest to that of Anthropocene. This is also the closest predecessor of Lotman's semiosphere in geology.

The main difference between the concepts of the semiosphere and the Anthropocene is that while the reality of the Anthropocene can only be understood as negative, as a disturbance of the harmony and stability of the Holocene, the semiosphere is not negative or positive. To acknowledge the semiosphere is simply to acknowledge the semiotic implications of the biosphere. Certainly, Lotman's concern was cultural criticism, while the concept of Anthropocene remains a geological notion, referring to the post-Holocene geological age, characterized by the loss of ecological equilibrium as caused by the "brainpower and technological talents" (Crutzen 2006: 13) of humankind. Thus, semioshpere is mostly a discursive concept, while Anthropocene refers to a geological era, on its object level. A split can be noticed here between the natural sciences' claim for objectivity, on the one hand, and the relativism of the humanities, and cultural studies in particular, on the other. Supposedly, the Anthropocene can be described quantitatively, and boundaries of "safe operating space" (Rockström et al. 2009) can be drawn, while the semiosphere is supposedly composed of texts of infinite potential interpretability, where boundaries are "abstractions, and are often described as series of bilingual filters or membranes that are by definition permeable and fluid, on the one hand, and as areas of accelerated semiotic processes, on the other" (Andrews 2003: 33, see Lotman 1990: 131140). An advantage of the Anthropocene as a concept is its inherent realism, namely that the Earth system finds itself in a certain state, regardless of any (mis)interpretations, and that, due to human activity, it shows an evolution that threatens the survival of many species, among them humans, who must find this alarming. The advantage of the concept of the semiosphere is that it explains the relative freedom of living beings to make models of the Earth system. As some of us have argued elsewhere (Olteanu 2015; Olteanu in Stables et al. 2018: 103-104), living organisms unavoidably change the environment even by simply learning about it, as the activity that all organisms perform continuously (also according to Sharov, Maran, Tønnessen 2015; Campbell 2018, 2019; Pikkarainen 2018). Herein lies the rationale of the present paper, namely the bridging between these two traditions of systems thinking or, more precisely, of using systems thinking to bridge natural sciences and cultural studies. We consider that a pathway in this regard is Stjernfelt's $(2007,2011,2014,2015 a)$ reading of Peirce, particularly in 
respect to Peirce's notions of icons and propositions. From this point of view, we propose the notion of the Universe of Discourse as an instrumental concept for understanding the relation between human modelling and the Earth system. The present network analysis of three decades of environmental research illustrates this approach.

Lotman's modelling theory, as a methodology, was inherited in biosemiotics, where, arguably, Sebeok further refined it and loosened its theoretical anthropocentric and language-centred claims. That the biosphere implies a semiotic "envelope" was explicated more insightfully in biosemiotics, by the argument that, as Lestel (2011[2002]: 388) puts it, "the biological form should be understood first and foremost as a sign". As such, there is an interdependency between biological form and representation. As concerns the present study, this implies that scientific theories must be formulated in ways adequate for human embodiment. Similarly, and in accord with Peirce's take on the representation of logic (CP 4.561, see Section 3.1 above), Elleström $(2018,2019)$ argues that a model of communication has to be represented both verbally and nonverbally as a diagram, because nonverbal communication cannot be (fully) understood in analogy to verbal communication. In a similar manner, this study represents environmental research in such twofold modelling, as semantic networks are diagrams represented both graphically (see the figures in Supplementary Material) and analytically, which is to say, algebraically (see the tables in Supplementary Material). More than focusing on any of these two models in particular, the semiotic analysis draws on the translation therein. The algebraic and arithmetic description of the corpus facilitates mental, simulated models in the form of image schemata. As usual, the graphic diagrams are more useful for abduction, that is, intuitionally formulating hypotheses, and the algebraic, numerical descriptions of the networks are more useful for the precise formulation of arguments and for confirming or refuting hypotheses (deduction and induction).

From this point of view, ecosemiotics, the ecological theory implied by biosemiotics, is preferred as an approach to culture in comparison with (what here is termed) text semiotics, or other anthropocentric cultural theories. The rationale of the emerging environmental humanities resides in the observation that culture and the environment, while obviously not coinciding, cannot be dissociated. The topic of this study is not culture or cultural theory, but environmental modelling theory and methods, their impact on culture, and the impact of human culture on the environment. As Maran and Kull (2014: 41) explain, the purpose of ecosemiotics is to investigate "the impact of maps on the mapped, on the landscapes, on the geographical systems". The linear, monomodal, textual language-centred and, implicitly, anthropocentric representation of the 
environment, such as in classic nature writing and also in much research, impacted on environments correspondingly, contributing to the (re)shaping of the Holocene into the current Anthropocene. This suggests the relevance of carrying out environmental research from the iconic turn perspective. As Crutzen (2006: 13) mentions, the geological era of the Anthropocene started with James Watts' design of the steam engine, being thus marked by human technology's impact on the Earth system. However, we argue that it is not only engineering that is responsible for this imbalance. Humans' representation of the environment and of themselves - their culture and (theoretical) science - have played a critical role in it. Thus, the effect that the media have on the Earth system(s) has to be considered. Environmental sustainability is a matter of media culture and, implicitly, media literacy. The printing press is the first suspect to be investigated as to how it contributed (or not) to the Anthropocene, followed by broadcasting and digital media, and also, going back in time to what first facilitated the perception of a form/ content dichotomy, the alphabet, together with other writing systems.

In regard to epistemology, biosemiotics as a modelling theory reveals that scientific theories, understood as modelling superstructures, while possibly aided by language, can also bypass language and be understood irrespectively of specific cultural traits. Thus, scientific models can well consist of nonverbal, schematic signs. For the biosemiotic theory it does not suffice to suppose that modelling starts prior to language, but also that complex theories can be developed aside (natural) language. As it stems from Sebeok's definition, meaning is continuous from biological to logical modelling: "A model [...] is a semiotic production with carefully stated assumptions and rules for biological and logical operations" (Sebeok 1991: 57). As such, he explained that the modelling operations involved in, for instance, the social organization of bees are the same as those involved in scientific modelling or in artistic production (see Sebeok 2001: 148-149). Particularly, he exemplified this by referring to Albert Einstein's own account of his scientific breakthrough, which developed via what in current terminology would be called 'schemata':

Einstein $[\ldots]$ constructed his model from nonverbal signs, "of visual and some of muscular type," and labored long and hard "only in a secondary stage" to transmute this creation into "conventional words and other signs," so that he could communicate it to others. "The words or the language, as they are written or spoken," Einstein wrote in a letter to Hadamard (1945: 142-143), "do not seem to play any role in my mechanism of thought. The psychical entities which seem to serve as elements in thought are certain signs and more or less clear images which can be 'voluntarily' reproduced and combined." (Sebeok 1991: 57; 2001: 148) 


\section{Semantic network analysis as a method in ecosemiotics}

As ecosemiotics is primarily defined as "the study of the semiotic interrelations between organisms and their environment" (Nöth 1998: 333) or, equivalently, as the study of "human relationships to nature which have a semiosic (signmediated) basis" (Kull 1998a: 351), we propose this theory as an epistemological basis for the postmodern, digitalizing and globalizing stage of the Anthropocene era (Crutzen, Stoermer 2000; Crutzen, Steffen 2003). Postmodernism, broadly understood as the relativizing of knowledge (e.g., Lyotard 1984[1979]), particularly in the current context of globalization accelerated by digitalization, has been a hotbed of relativist text semiotics. The present analysis recommends a different epistemological dismissal of mind/body dualism than such relativization and consequent skepticism towards the scientific claim for factuality. More recent research (e.g., Deely 2001; Stjernfelt 2007) finds in Peirce's semiotics an alternative, realist, and not relativist, candidate for postmodernism. As mentioned above, not only semiotic theory, but also digital technology is necessary for such modelling that renders a large and complex theoretical corpus descriptive of environmental facts and tendencies.

We rely on Charles Peirce's typology of signs, as explored in its capacity for constituting a modelling theory (Anderson, Merrell 1991; Sebeok, Danesi 2000; Nöth 2018; see also Olteanu, Stables 2018), particularly adequate for schematic representations (Stjernfelt 2007; Kralemann, Lattmann 2011, 2013). In line with Peirce's concept of sign, and compatibly with Lotman's notion of the model, Sebeok and Danesi (2000: 2) defined 'model' as "a form that has been imagined or made externally (through some physical medium) to stand for an object, event, feeling, etc., known as a referent, or for a class of similar (or related) objects, events, feelings, etc., known as a referential domain".

In an effort to bring together semiotics and ecosophy (e.g., Næss 1988; Guattari 2013), Levesque (2016: 511) notices that these two share modelling as a common concern and argues that, from the points of view of Peirce and Sebeok, semiotics "does not produce new scientific data, it can suggest new ways of organizing the data made available by special sciences (or ideoscopic sciences) and, in doing so, it can help connecting specific knowledge through a unifying systemic model. The results obtained by cenoscopic methods may in turn have repercussions on ideoscopic sciences - a change in modelling leading to a change in practices" (Levesque 2016: 514). The present study consists in such an organization of data, via semiotic modelling, advancing ecosemiotics to cenoscopic (CP 1.241) and idioscopic (CP 1.242) stages. 
Also, Kralemann and Lattmann's Peircean-based theory of models, developed in view of the central role that iconicity plays in Peirce's semiotics, particularly as accounted for by Elleström (2013a, 2013b; see also 2018, 2019), was proposed as a fitting theory for digital humanities research methods (Ciula, Eide 2016; Ciula, Marras 2016, 2019). The focus on iconic (schematic) signification is particularly suitable not only for digital modelling, where semantic networks are an exemplary illustration, but for ecosemiotics as well. The iconic turn is also one of the main causes that revealed the need for a semiotic theory of ecology, whereby (human, symbolic) culture is not understood as detached from nature:

Ecosemiotics has partly emerged due to the deepened understanding of the nonsymbolic sign processes' role in the research objects both in biology and the humanities. Most ecological communities involve human communication and action but human conscious control is only partial even in thoroughly artificial ecosystems. In many recent approaches in the humanities, such as posthumanism and ecocritical studies, the conception of purely cultural objects has been problematized. These observations point to the need for an interdisciplinary reordering that would allow their models to perceive the natural environment as influenced by human signifying and modifying activities and cultural texts, and to be rooted in the human perception of the environment and bodily engagement with that environment. (Maran, Kull 2014: 42)

According to Peirce, a sign is "something which stands to somebody for something in some respect or capacity" (CP 2.228). This definition, with the theory of signification that Peirce subsequently developed, led Kralemann and Lattmann to argue that "models can and should be understood as signs", given that, like signs, models "stand for their originals and thus represent them" (Kralemann, Lattmann 2011: 51). Certainly not all signs are (scientific) models. For instance, words do not (necessarily) function as models. A word does not represent its object in a way that renders the object particularly maneuverable in some regard. For this reason, Kralemann and Lattmann (2011: 52) consider that "models are nothing but "icons", signs (or, as is equivalent, specific aspects of an object acting as a sign) that, according to Peirce, represent their semiotic objects by resembling them (see e.g. CP 2.243-253 [...])". While we agree with them as regards the necessity for iconic signification in models, we also consider that other, more complex sign types can serve as models, each with their particular insights, as also claimed by Nöth (2018). Such are signs that incorporate icons in their constitution, like, for example, symbols, predicates, propositions and arguments. For this reason, Kralemann and Lattmann's theory of models as icons fundamentally stands. While all of these more complex signs require an icon of a particular kind in 
their constitution (e.g. CP 2.248-2.249, Stjernfelt 2007: 37, 42-43), when used as a model that particular, incorporated icon must be highly salient. Thus, for someone who excellently masters a conventional language, the words of that language participate in the modelling of reality.

It is important to keep in mind, as Nöth (2018: 40) explains, that, according to Peirce (e.g., CP 4.448), ideally, a model pragmatically combines sign types, according to the different modelling values of different types. However, because of the prevalent symbolic layer of languages, modelling with words can be strenuous, particularly if the object to be modelled consists in a vast number of highly technical and theoretically complex concepts. While combining various sign types, the object that we are here looking at (a corpus of environmental research) claims to stand in a strong iconic relation to the state of the Anthropocene. This is its rationale. The translation of environmental dynamics into human, scientific language can result in models that miss some important aspects of their object(s). While we are actually adding yet another layer of representation (the network-like models) to this representation of the environment, we argue that this added layer reveals more faithfully the state of the environment, thus confirming its iconicity with the research corpus. In this case, language, as used to develop environmental science, is an aid, or a scaffolding to modelling, not the model itself.

As such, both new arguments and errors in our scientific understanding of the environment can be revealed by bringing to the fore the iconic aspects of a model. Language has been used to describe various phenomena and analyse them in detail, but this has led to a vast corpus, difficult if not impossible to analyse by close reading, as the habitual scholarly practice. An easily maneuverable icon or set of icons of this corpus, which we here draw in the form of semantic networks, is necessary. Certainly, this is not to say that every piece of research (included in the corpus) is, in a sense, "correct", but that, overall, science is more revealing than not, that the environment can actually be described, and that future tendencies can be anticipated on account of how things factually are at present. Hence, we claim that such a methodology evidences that results of environmental research, such as that the climate is changing due to human activity, are not relative to the culture and interests of academic communities to the point that they could be ignored or denied. Also, it accounts for more subtle, but not less important insights, such as the niche-organization of research, in either more revealing or redundant ways. For instance, climatization tendencies, namely the relativization of concepts in environmental research to climate change to the point of marginalizing other planetary boundaries, as well as other biases, can be observed in the evolution of the networks. 
Also, conceptualized as semiosis, the evolution of the structure of semantic networks describes how the community of researchers communicates. Semiosis is Peirce's concept of interpretation, which he defined as "an action, or influence, which is, or involves, a cooperation of three subjects, such as a sign, its object, and its interpretant, this tri-relative influence not being in any way resolvable into actions between pairs" (CP 5.484). The evolution of the structure of the network cannot be conceived as the evolution of dyadic relations, that is, of pairs. A repositioning of a node within the graph reconfigures a set of relations (e.g., by changing the degree of centrality of the node) and can imply the rewiring of other nodes as well. Also for this reason, looking at research corpora as networks is insightful, as the effects of an apparently local change can be traced through the entire edge list. Peirce defines interpretation, as well as signs, as triadic, on account of his logical demonstration that any graph of a degree higher than three is reducible to a third degree graph. Third- and second-degree graphs are not reducible. Also, any monadic or dyadic entity necessarily implies its own evolution into a triadic one (e.g., predicates are unsaturated propositions, propositions are unsaturated arguments). For this reason, biosemiotics, in which our method is rooted, considers that all instances of evolution involve co-evolution not only of species, as co-evolution was initially construed, but also of any evolving traits and semiotic competences (as exemplified in Deacon 1997; Schilhab, Stjernfelt, Deacon 2012; Hoffmeyer 2008: 179).

In light of his triadic notion of sign and semiosis, Peirce conceived of three phenomenal categories in view of which meaning is analysable. He plainly termed them Firstness, Secondness and Thirdness (CP 8.327-331). Firstness is the category of monads, characterized by infinite possibility, and it describes the Sign in Itself, the sign's Representamen as Peirce termed it. Secondness is the category of dyads, being characterized by opposition and brute material restriction. It describes the Representamen's relation to its Object. Thirdness is the category of triads, described by laws, or tendencies, or habits (terms that are interchangeable in Peirce). It describes the sign in its interpretative, conclusive character, which Peirce termed Interpretant. Sebeok and Danesi (2000) used Peirce's categories to extrapolate a modelling theory as the main method of semiotic analysis. Semiotics was, of course, conceptualized as a modelling theory before this development. As mentioned above (see Sections 3.2 and 3.3), Lotman (1977) was the first to discuss explicitly meaning phenomena as modelling devices, which is one of the sources of inspiration for Sebeok's biosemiotics.

Thus, according to the Peircean definition of the sign, the models that we are analysing are seen as standing for the states of affairs in environmental sciences and their tendencies, as captured in corresponding moments. More importantly, 
in turn, they stand for the state of the Anthropocene itself, not in a holistic way, but as pragmatic models conveying specific information about it.

Peirce's pragmatism is anti-atomistic: existence and reality are relational, nothing can exist in a monadic state. In the same way, a concept being represented as a node in the semantic networks of concepts that we are looking at means that the concept is co-present in at least one article (abstract) with at least one other concept in the corpus. This means that there is at least one path from any given node to any other node in a network. For this reason, these semantic networks have the structure of a Peircean web of signs: semiosis is continuous. According to Peirce, a relation between two entities already contains the relation itself as a third element. A dicisign (see Section 3.2 above), as the association of an index to an icon, where the index has the function of subject and the icon is used as a predicate to describe the subject, is already a triad. There is no, so to say, innocent correlation. In view of this concept of proposition, Stjernfelt (2014: 108-114) recently developed a semiotic account of pairing, which he termed co-localization. The main idea is that the (spatio-temporal) proximity of two elements is meaningful, always involving a Subject-Predicate manner of coupling. As a result, the dicisign sign type has a pivotal role in an organism's experience and organization of the environment. Co-localization constitutes the propositional syntax of the biological world. From this perspective, the co-occurrence of concepts, represented as an edge connecting two nodes, is understood as a dicisign in the models that we analyse. In the same logic as Peirce's notions of 'line of identity' (CP 4.406) and 'ligature' (CP 4.407), an edge makes an assertion: namely, that there is an existential relation between its two termini. As the networks are weighted, the edge also describes the level of iconicity of the relation, as relative to the entire network. Since edges are undirected, in most cases it cannot be said which node represents the subject and which one represents the predicate in a particular dicisign. However, by looking at network structures in their complexity, it is possible to tell how a node functions as a predicate or as a subject in a certain web. One clue is given by Peirce's understanding that, in a dicisign, an infinite number of subjects can be applied to one predicate (CP 2.272; see Stjernfelt 2015a: 1025-1026). Thus, it can be inferred that a node with a high value of degree centrality functions as a predicate for many subjects in the network. This means that networks with undirected edges actually have a hermeneutic advantage, despite an apparent imprecision: they allow for the localized interpretations of constituting webs.

As a whole, the network model is an icon, of course, but propositional signs can be observed in its constitution, the coupling of which results in the discovery of arguments in the corpus. These arguments might not be explicitly addressed 
in the linguistic incarnation of the research. They are implicit and, so to speak, "located between the lines". Semantic networks reveal them explicitly, by bringing to the fore the iconicity that gives the corpus its continuity. Hence, co-occurrences, represented in the graph as edges connecting nodes, are justifiably propositions, as they indicate a co-localization. This is one more regard in which the semantic network of a large corpus of texts, understood semiotically, conveys information that is rather obscure in the original, language-constituted corpus.

Stjernfelt (partly) disagrees with the classic semiotic modelling theory as developed by Sebeok and Danesi (2000). While semiotic modelling theories classically considered a parallelism between semiosis and cognition, namely that more complex cognition corresponds to more complex meaning, Stjernfelt's reading of Peirce implies that complex semiotic structures can be grasped by biologically simple organisms that do not necessarily require complex central nervous systems (see Hoffmeyer, Stjernfelt 2016). Rather, biological complexity is needed for the communication of the apprehended signs and, more importantly, for modelling: by dissecting complex structures of meaning into their simpler, composing signs, these structures appear more maneuverable for the organism, while also new semiotic resources for further modelling are discovered. Sebeok and Danesi (2000: 10) undertook the common conceptualization in semiotics that meaning develops from simple to complex, along Peirce's phenomenal categories, thus establishing a correspondence between three (layers of) modelling systems and the phenomenal categories. Stjernfelt's view implies that the dicisign sign type, which describes an Interpretant (Thirdness) on its Object level (Secondness), plays a pivotal role in modelling because it makes both simpler and more complex signs accessible. This is a crucial aspect of network analysis, because, following Stjernfelt (e.g., 2015a: $1025,1032)$, the co-localization hypothesis implies that network-like structures represent simultaneously indicatively and qualitatively ${ }^{6}$.

\section{Iconic turn perspective on semantic networks}

In the relativist tradition of discursive theories - the philosophical mainstream of the second half of the 20th century - representation came to be understood as only providing evidence for previous (via deconstruction) or further representation, but not for any aspect of a supposedly mind-independent reality. A characteristic of Peirce's semiotics is that while it accounts for that meaning infinitely produces meaning, meaning first consists in a mediation between mind-dependency and

6 Arguably, this challenges Nöth's (2018: 12) consideration that classes of signs that are (preponderantly) indexical cannot be used as models. 
mind-independency (e.g., Deely 2001, 2009). In this view (as evidenced by Sebeok 1991, 2001), the environment of any biological organism consists in meanings and any conception of a purely non-material idea or an interaction with purely non-mental matter is an abstraction (useful for mental experiments, but nothing more). Thus, in a Peircean reading, data are always related to empirical facts that they evidence (Feil, Olteanu 2018: 218-219). In the case of an erroneous collection method, the data would (at least) suggest the mismatch between collection and the intended modelling by resulting in models that are not unfalsifiable, but actually false. The mismatch is evidenced by the impossibility (or absurdity) of the proposition consisting in the application of (1) a predicate resulting from the supposed iconicity between the data and the object of study to (2) the object of study as subject. If the proposition is possible but false, then it is simply the case that a hypothesis is refuted or needs reconfiguration (or, in Peircean terms, abduction). Whether the proposition is true or false is to be decided (induction), but the proposition, that is, a sign that distinctively indicates the object to which a predicate is applied, makes a truth-claim (Stjernfelt 2011, 2014, 2015a; CP 2.310). In this view, no model can be purely mental in the sense that it would entirely avoid physical constraints and possibilities, nor can it be entirely confused with its object. Representation always starts from operations on qualities (CP 2.2432.244, 2.254; see Stjernfelt 2007: 25-26), which open up the possibility of iconic manipulation (discovery of shared qualities). Thus, a continuity of similarity runs all throughout representation, from the simplest perceptions to sophisticated scientific theories (see Stjernfelt 2007: 29-30). This underpins one of the founding realizations of ecosemiotics, namely that "the organism's inner world contains [...] a cognitive model of its umwelt" (Nöth 1998: 339). In the context of the linguistic turn, this aspect of Peirce's semiotics, in particular, has been left aside, resulting either in its misuse or avoidance (Stjernfelt 2007: 51). The models resulting from our computation of the selected sample are understood as icons.

Semantic network analysis is "the use of network analytic techniques on paired associations based on shared meaning as opposed to paired associations of behavioral or perceived communication links" (Doerfel 1998: 16). As a semantic analysis method, such network analysis can be considered, in the realm of semiotics, as a particular type of semiotic analysis method. Its being concerned not only with meaning, but with shared meaning in particular, recommends conceiving this method within a broader semiotic modelling theory. Since semantic network models are webs (graphs) of meaning relations, they act as icons or sets of icons in the Peircean sense. The icon is a sign that signifies due to similarity to its object, denoting it "by virtue of characters of its own" (CP 2.247). This is important for (cognitive) modelling because, as Brandt (2011: 
51) mentions, "[i] conic signs show what is possibly true", in contradistinction to dicisigns, which not only represent a possibility, but actually make a truth-claim.

While we focus on shared meanings as particular for semantic networks in contrast to social networks, and argue that concepts do not have a behaviour of their own, unlike living organisms, we also take into consideration that network structures inherently present communicative phenomena. From the semiotic perspective that we employ, a link (edge connecting nodes) is an act of communication: a correlation represents conveying of information. As a typical semiotic scope, this is, in brief, the main difference between semantic network analysis as traditionally conceived and its semiotic conceiving in view of a broader modelling theory and methodology that we are advocating. Through its structure, a network communicates. To begin with, a semantic network of environmental research communicates the state of the art of such research and, we argue, the state in which the Anthropocene finds itself. Such a comprehensively communicating model was not observable otherwise than through the digital computation of a large amount of data, now possible due to technological computation devices. If Earth system science is not graspable for the broad public (or even for specialized researchers), which has to make political and social decisions in view of the state of the Anthropocene, its representation in networks makes eligible truth-claims towards which, at least, no interpreter can remain neutral.

An implication of Peirce's schematic semiotics that constitutes another advantage of analysing semantic networks is that it accounts for the possibility of a predicate to be applied to a multitude (potential infinity) of subjects (Stjernfelt 2007: 31, 2014: 57; CP 2.272; see Stjernfelt 2015a: 1025-1026; see Section 4 above). This is contrasted, in general, to the linearity of propositional logic in philosophy of language and linguistics, which have mostly underpinned text analysis methods (see Stjernfelt 2015a: 1020). Thus, a (sub)structure of a network consisting of a node connected (through edges) to several other nodes can be understood as one proposition consisting of one predicate ('... is connected to') and several other subjects (Node 1, as connected to Nodes 2, 3, etc.), and not only as a set of propositions (which might not be as revealing).

The semantic networks of concepts in the environmental sciences are understood as diagrammatic (iconic) models of state-of-the-art environmental research. The claimed iconicity between the network and a greater corpus counts as evidence. Even more, the iconic modelling of the corpus presents evidence for the processes occurring at the Anthropocene and biosphere level(s). Without the possibility of an operational representation of the corpus of environmental research, comprehensive of its entirety, there can be doubt as to whether such research is actually truthful about the environment. A graspable model of this 
research is interpretable and provides evidence. Peirce's taxonomy of signs implies that the syntax of propositions, the Subject-Predicate copula, accounts for the individual proposition's indexical connection to its denoted object (see Stjernfelt 2014: 66-67). As Peirce explains:

It may be asked what is the nature of the sign which joins 'Socrates' to '_ is wise', so as to make the proposition 'Socrates is wise'. I reply that it is an index. But, it may be objected, an index has for its object a thing hic et nunc, while a sign is not such a thing. This is true, if under 'thing' we include singular events, which are the only things that are strictly hic et nunc. But it is not the two signs 'Socrates' and 'wise' that are connected, but the replicas of them used in the sentence. (EP2: 310)

This theory of propositionality entails a realist epistemology in contradiction to the relativism of mainstream text semiotics. It supposes a certain hic et nunc effect of representation that is critical for biological research. Unlike anthropocentric theories of culture, some branches of semiotics such as bio- and zoosemiotics (Kull 2015, 2018; Martinelli 2010: 70), but not only these (e.g. Stables 2012), acknowledge spatiotemporal presence and proximity, understood subjectively according to organisms' umwelten, as critical in meaning-making and, hence, modelling.

The advantage that iconic signs (used as predicates) have for such modelling is that, unlike the otherwise indispensable linear language in which the research was initially carried out and represented, they render a very large amount of content operational in one framed snapshot. The justification for Peirce's coining of iconicity as a crucial aspect of representations of logic consists in the spatial mediality of logic (see Section 2 above; Stjernfelt 2015b: 38; Bellucci 2013). According to Stjernfelt (2007: 99), operating on diagrams such as networks "can make explicit (parts of) the signification of a symbol and pragmatically weed out symbol inconsistencies". This is so because of the schematic character of networks: they represent the concepts as related nodes and the inter-relations between concepts as edges of a graph. Thus, the semantic content of concepts is not supposed in a conventional way (e.g., a human cultural convention projected on the environment), but it stems from the logical relations that constitute the graph, that is to say, from the place that the node occupies in the graph. Due to this schematic structure, networks are a particular type of icon, namely diagram. Diagrams, in general and according to Peirce's typology, signify due to inner structural similarities or, in other words, due to part-whole similarities consisting in a sign's inner analogies. This makes diagrams highly operational signs, as Stjernfelt explains, "mirroring real laboratory experiment on a conceptual level" 
(Stjernfelt 2007: 47). Peirce defines them as belonging to a particular category of icons, namely hypoicons (CP 2.277), together with images and metaphors.

Thus, a semantic network contains information according to its inner relations (intrinsic similarities): a node's centrality, or term-frequency, inverse-document frequency and their ratio, or entropy are meaningful relative to the rest of the network. Diagrams contain images, partaking of "simple qualities" (CP 2.277) and are required in the development of metaphors, that is, analogies to "something else" (CP 2.277). Thus, grounded in environmental research as diagrammatic, an environmentally-minded culture and epistemology can be conceived as metaphorical: for sustainable development, culture has to mirror the environment (and not the other way around, as relations of signification suppose a direction).

\section{Interpreting the Earth system science corpus modelled as semantic networks}

Weighted networks, such as we are looking at, where the centrality of a node can be measured as either a result of the number of its edges, the sum of their edge weights (following the method of Opsahl, Agneessens, Skvoretz 2010), or some approach in between, show how strong the indexicality (supposed causality) between two concepts is. A higher value of a node's weighted degree centrality means a more central place in the network for the respective node. The value of an edge's weight shows how closely co-located the nodes linked by the respective edge are. The higher an edge's weight value is, the more saturated the proposition it represents is and, hence, the more likely it is for that proposition to contour an argument in the context of the network. Thus, (at least) in the case of weighted networks, Stjernfelt's (2015a: 1032) hypothesis of co-localization as "a primitive, pre-linguistic syntax sufficient to connecting the subject and the predicate tokens as a sign of the combination of the subject and predicates themselves in a proposition" supports Lotman's view that the language proper of a system is located in the system's centre (Stjernfelt's focus on mereology being otherwise quite different from Lotman's rather holistic view of systems). The nodes that have the highest values of weighted degree centrality form the subject of the network, as a whole. Such are, for instance, the concepts of 'climate,' 'atmosphere,' 'water', 'temperature', 'surface,' 'soil' (see Table 1. "Weighted degree centrality of central concepts", in Supplementary Material).

These concepts, together with those of 'region' and 'soil', form a core subject of Earth system research, around which the evolution, emergence and disappearance of other concepts in the corpus revolves. Particularly, 'climate' stands out as more 
salient than other central nodes. The lowest value of its centrality is 3.68, in 1990, which suggests an increase in interest in climate in the early 1990s. Between 1991 and 2017, the weighted degree centrality of climate increased significantly (it only decreased by very little in 2016). This means not only that Earth system research spins around the issue of climate but also, in view of Lotman's (1990: 124-130) understanding of centre/periphery semiotic dynamics, that it is becoming a science dedicated to investigating climate. Climate is the dominant language of Earth system science. Peirce's mereological semiotics, in light of Stjernfelt's (2007, 2011, 2014, 2015a) investigations on Peirce's predicate and propositional logic, further offers a more precise reading. What the semantic networks thus show is that a concept has its place in Earth system science according to how it can be applied as a subject to climate as the predicate. Vice versa, a concept that can serve as predicate, applied to climate as subject, while also accepted in the network widely (i.e., belongs to one of the constituting semantic communities and can thus form dicisigns with other nodes as well), is very likely to dominate future debates. Thus, we argue that this is a good premise for correct abductions about successful future topics. This can also be an interesting consideration for researchers and a biasing observation for science, as it can suggest ways to speculate what topics are likely to gather impact as a technical metric, rather than scientific goals.

Climatization, as noticed in the metrics of the 'climate' node, is possibly noticed in other areas of environmental sciences, too. The process of climatization in the corpus is noticed also by the high value of weight of the edge between climate and change. Overall, the weight of this edge is 0.38 , tending to increase. In 1990, the weight of this edge appeared to be rather low, namely 0.06 , but, again, this can be interpreted as stemming from lack of digitalized data for that year. From 1991 to 2018 the weight of the 'climate'-'change' edge increased, although with some fluctuations (see Table 3, in Supplementary Material). It peaked in 2011.

The concepts system, ecosystem and model appear rather salient as well, which confirms that the dataset is descriptive for the Earth system science corpus. They have been undergoing centralization as well (see Table 2. "Weighted degree centrality of concepts of main interest", in Supplementary Material). The concept of 'biodiversity' is surprisingly little represented, given its relevance for environmental governance (weighted degree centrality values spanning from 0.03 , in 1993, to 2.57, in 2017). Nevertheless, the trend for this concept is ascending. While slow, the centralization process of 'biodiversity' is possibly inspired by the planetary boundaries framework. However, the increase in centrality of 'biodiversity' appears constant, with no particular accelerations corresponding to the emergence of this framework after 2009. 
As to focused interests shared with ecosemiotics, the term 'ecology' is, on the one hand, not well represented, but, on the other hand, in an ascending trend. Its centrality has been spiking recently. This might suggest an opportunity for an ecological turn in Earth system science, which can be supported, as we show here, by the spreading of digital computing methods. The emergence of the planetary boundaries framework as a systems science approach to ecology is likely to be another cause for this. The comprehensive insight thus suggested is that systems science starts having proper applications in environmental research together with the emergence and use of powerful computing tools in research and the emergence of digital humanities. Also the presence of the term 'map' is noticeable, as an ecosemiotic concern, albeit rather peripherally situated. This node has also been slowly centralizing, from the lowest value of 0.87 , in 1991 , to peaking at 3.66 , in 2015 , and to slightly decreasing to 3.48 , in 2017 . This might indicate an opportunity to addressing representation (mapping) in environmental research.

The number of semantic communities, identified as corresponding to semantic fields, that compose the networks is relatively stable. Nevertheless, a slight tendency of it to decrease slowly over time can be supposed. In their turn, the semantic communities of a semantic network must be understood diagrammatically, as component parts of the network with some relative independence. Five semantic communities were observed in 1990 and, until now, three have been observed starting with 2013. In between these moments, the number of semantic communities has been fluctuating between three and four. The small and decreasing number of communities might manifest a consolidation of the corpus in a few stable clusters. This should be understood in view of the gradual increase in concepts and their absorption into a shrinking number of communities

The salience of semiotic concerns in the corpus is primarily suggested by the presence of the concepts 'signal' and 'signification'. While nevertheless relevant in this regard, 'signal' might denote an understanding specific to environmental sciences, aside the common acceptance in semiotics, and it is rather peripheral. The main concern of semiotics, the concept of 'signification', on the other hand occupies a central position, peaking in 2009. The use of this term illustrates an epistemology of semiotic inclination. In 2016 and 2017 'signification' remained rather central. Moreover, 'signification', 'signal' and 'similarity', the latter being a term particularly relevant for schematic semiotics (i.e., iconicity), appear co-present in the corpus with 'model. The overall weight of the edge 'model''signification' is relatively high, namely 0.114 . This means that a dicisign where model is subject and signification is predicate, or vice versa, is very useful for developing arguments in Earth system science. The overall weight of 'model'- 
'signal' is 0.018 and that of 'model'-'similarity' is 0.078 . These values are not particularly high, but mark a certain co-localization, nevertheless. Other metrics involving the node 'model' reveal, perhaps even more convincingly, an opportunity for semiotic methodologies in Earth system science.

For instance, the overall weights of the edges 'change'-'model' and 'climate''model' are considerably high and similar, not surprisingly, given the centrality of 'climate' and weight of 'climate'-'change' (see Table 3. "Edge weights for 'climate'-'model', 'climate'-'change', 'change'-'model' and 'model'-'signification", in Supplementary Material). Thus, the triad 'climate'-'change'-'model' should be considered as a (Peircean) sign. To do so, a common meeting point must be induced, as a sign is not merely a sum of three elements (nodes or edges), but their genuine, simultaneous cooperation that cannot be reduced to the relations between them. This is not a simple endeavour and, for this purpose, a more meticulous analysis of the networks is necessary. The triad certainly constitutes a sign, but just how its semiosis proceeds in the overall corpus is rather difficult to determine. Putting the matter in Peircean terminology, we do not know which of the termini acts as Representamen, which as Object, and which as Interpretant. The question is what stands for what (and in what way) in the Universe of Discourse of Earth system science? One semiotic relation that can be inferred is that the sign 'climate'-'change'-'model' is an index for Earth system science, in general. This does not mean that this triad does not act as sign in other universes of discourse, nor that other signs do not have a similar relation with this corpus. It reveals, though, how to involve Earth system science in an interdisciplinary inquiry: a predicate must be found that can take climate-change-model as a subject, together with other subjects that belong to research corpora other than Earth system science.

Other triads worth considering for determining the semiosic activity of 'climate'-'change'-'model' in the corpus are 'signification'-'change'-'model', 'signification'-'climate'-'model' and 'signification'-'climate'-'change'. In this regard, it is remarkable that the weight of the edge 'model'-'signification' has been steadily increasing in the corpus, from 0.02, in 1990, to 0.12, in 2018, having picked in 2002 with 0.13 . These values are, as well, comparable to the weights of 'change''model' and 'climate'-'model'. Also, the overall weights of the edges 'climate''signification' and 'change'-'signification' are considerable, namely 0.14 and 0.16 , respectively. These values seem to increase proportionally with those of the weights of 'climate'-'model' and 'change'-'model'. Hence, a correlation is observed as to how 'signification' and 'model' are situated in regard to the dicisign formed by 'climate' and 'change'. 
Overall, we suggest that these observations point to the possibility of a semiotic turn in environmental sciences, which also explains, in part, the recent emergence of environmental humanities. According to Sörlin (2012: 788), the concern for the environment in the humanities, as well as vice versa (humanistic concerns of environmental research) is bound to the Earth system approach, "as the shift toward the human sciences has to do with the fundamental shift in understanding that is represented by the Anthropocene concept". The Anthropocene is too complex and vast a system to be grasped in classic, monomodal text descriptions. Rather, the organization of large amounts of environmental data in models, possible due to digital technology, makes the Anthropocene comprehensible for the human mind. Particularly, semantic networks are excellent models in this regard, an argument which has been implicit in semiotics for a long time, starting from Peirce's concepts of sign, semiosis and universe of discourse, in its interest for systems thinking and its definition of systems as webs of signs (e.g., CP 1.371; Lotman 2009 :77; Sebeok, Danesi 2000: 15). ${ }^{7}$

\section{References}

Anderson, Myrden; Merrell, Floyd (eds.) 1991. On Semiotic Modeling. Berlin: Mouton de Gruyter.

Andrews, Edna 2003. Conversations with Lotman: Cultural Semiotics in Language, Literature and Cognition. Toronto: University of Toronto Press.

Archer, Margaret 1995. Realist Social Theory: The Morphogenetic Approach. New York: Cambridge University Press.

Bellucci, Francesco 2013. Diagrammatic reasoning: Some notes on Charles S. Peirce and Friedrich A. Lange. History and Philosophy of Logic 34(4): 293-305.

Bishop, Keith; Reid, Alan; Stables, Andrew; Lencastre, Marina; Stoer, Steven; Soetaert, Ronald 2000. Developing environmental awareness through literature and media education: Curriculum development in the context of teachers' practice. Canadian Journal of Environmental Education 5: 268-286.

Boehm, Gottfried; Mitchell, W. J. Thomas 2009. Pictorial versus iconic turn: Two letters. Culture, Theory and Critique 50(2/3): 103-121.

Bourdieu, Pierre 1990[1980]. The Logic of Practice. Stanford: Stanford University Press. Brandt, Per Aage 2011. What is cognitive semiotics? A new paradigm in the study of meaning. Signata: Annals of Semiotics 2: 49-60.

7 Acknowledgments. This research was supported by the Research, Development and Innovation Fund of Kaunas University of Technology (project SEMNET [PP32/1805]). Besides, Alin Olteanu's research on modelling is supported by the Estonian Research Council project MOBJD346 ("Towards a joint environmental and digital literacy: An ecosemiotic approach to digitalization”). The authors would like to thank Mark Alfano, Aistė Balžekienė, Rasa Kasperiené, Timo Maran, Dario Martinelli and Vaidas Morkevičius for the inspiring discussions. 
Campbell, Cary 2018. Returning 'learning' to education: Toward an ecological conception of learning and teaching. Sign Systems Studies 46(4): 538-568.

- 2019. Educating semiosis: Foundational concepts for an ecological edusemiotic. Studies in Philosophy of Education 38: 291-317.

Ciula, Arianna; Marras, Cristina 2016. Circling around texts and language: Towards "pragmatic modelling" in digital humanities. Digital Humanities Quarterly 10(3).

- 2019. Exploring a semiotic conceptualisation of modelling in digital humanities practices. In: Olteanu, Alin; Stables, Andrew; Borțun, Dumitru (eds.), Meaning \& Co.: The Interdisciplinarity of Communication, Semiotics and Multimodality. Cham: Springer, 33-52.

Ciula, Arianna; Eide, Øyvind 2016. Modelling in digital humanities: Signs in context. Digital Scholarship in the Humanities 32(1): i33-i46.

Cobley, Paul 2016. Cultural Implications of Biosemiotics. Dordrecht: Springer.

CP = Peirce, Charles Sanders. The Collected Papers of Charles Sanders Peirce. (Hartshorne, Charles; Weiss, Paul, eds. 1931-1935; Burks, Arthur W., ed. 1958.) Cambridge: Belknap. [In-text references are to $\mathrm{CP}$, followed by paragraph number.]

Crutzen, Paul J. 2006. The "Anthropocene". In: Ehlers, Eckart; Kraft, Thomas (eds.), Earth System Science in the Anthropocene: Emerging Issues and Problems. Berlin: Springer, 13-18.

Crutzen, Paul J.; Steffen, Will 2003. How long have we been in the Anthropocene era? An editorial comment. Climate Change 61: 251-257.

Crutzen, Paul J.; Stoermer, Eugene F. 2000. The Anthropocene. Global Change Newsletter 41: 17-18.

Deacon, Terrence 1997. The Symbolic Species: The Co-evolution of Language and the Brain. London: W. W. Norton \& Company Inc.

Deely, John 2001. Four Ages of Understanding: The First Postmodern Survey of Philosophy from Ancient Times to the Turn of the Twenty-first Century. Toronto: University of Toronto Press.

- 2009. Augustine \& Poinsot: The Protosemiotic Development. Scranton \& London: University of Scranton Press.

Doerfel, Marya L. 1998. What constitutes semantic network analysis? A comparison of research methodologies. Connections 21(2): 16-26.

Eco, Umberto 1976. A Theory of Semiotics. Bloomington: Indiana University Press.

Elleström, Lars 2013a. Introduction: Instrumental and formal iconic signs. In: Elleström, Lars; Fischer, Olga; Ljungberg, Christina (eds.), Iconic Investigations. Amsterdam: John Benjamins Publishing Company, 1-9.

- 2013b. Spatiotemporal aspects of iconicity. In: Elleström, Lars; Fischer, Olga; Ljungberg, Christina (eds.), Iconic Investigations. (Iconicity in Language and Literature 12.) Amsterdam: John Benjamins Publishing Company, 95-117.

- 2017. Transfer of media characteristics among dissimilar media. Palabra Clave 20(3): 663685.

- 2018. A medium-centered model of communication. Semiotica 224: 269-293.

- 2019. Modelling human communication: Mediality and semiotics. In: Olteanu, Alin; Stables, Andrew; Borțun, Dumitru (eds.), Meaning \& Co.: The Interdisciplinarity of Communication, Semiotics and Multimodality. Cham: Springer, 7-32.

EP2 = Peirce, Charles S. 1998 [1893-1913]. The Essential Peirce: Selected Philosophical Writings. Vol. 2. Bloomington: Indiana University Press. [In-text references are to EP, followed by volume and paragraph numbers.] 
Eriksen, Jens-Martin; Stjernfelt, Frederik 2012. The Democratic Contradictions of Multiculturalism. New York: Telos Press.

Fortunato, Santo 2010. Community detection in graphs. Physics Report 486: 75-174.

Foucault, Michel 2002[1969]. The Archaeology of Knowledge. (Sheridan Smith, A. M., trans.) London: Routledge.

Feil, Sebastian; Olteanu, Alin 2018. Abduction, hermeneutics and the interpretation of interpretations. Human Arenas 1: 206-222.

Georgeon, Olivier L.; Ritter, Frank E. 2012. An intrinsically-motivated schema mechanism to model and simulate emergent cognition. Cognitive System Research 15/16: 73-92.

Gould, Stephen J.; Vrba, Elisabeth S. 1982. Exaptation - a missing term in the science of form. Paleobiology 8(1): 4-15.

Guattari, Félix 2013. Qu'est-ce que l'écosophie? [What is ecosophy?] (Nadaud, Stephane, ed.) Paris: Lignes \& IMEC.

Hall, Stuart; Hobson, Dorothy; Lowe, Andrew; Willis, Paul (eds.) 2005[1980]. Culture, Media, Language. London: Routledge.

Halliday, Michael A. K. 2002. Linguistic Studies of Text and Discourse. London: Continuum.

Hartley, John 2015. Urban semiosis: Creative industries and the clash of systems. International Journal of Cultural Studies 18(1): 79-101.

Hoffmeyer, Jesper 2008. The semiotic body. Biosemiotics 1(2): 169-190.

- 2018. Knowledge is never just there. Biosemiotics 11(1): 1-5.

Hoffmeyer, Jesper; Stjernfelt, Frederik 2016. The Great Chain of Semiosis: Investigating the steps in the evolution of semiotic competence. Biosemiotics 9: 7-29.

Johnson, Mark 1987. The Body in the Mind: The Bodily Basis of Meaning, Imagination, and Reasoning. Chicago: The University of Chicago Press.

Kralemann, Björn; Lattmann, Claas. 2011. The semantics of models: A semiotic philosophy of science approach. In: Schewe, Klaus-Dieter, Thalheim, Bernhard (eds.), Semantics in Data and Knowledge Bases, Dordrecht: Springer, 50-69.

- 2013. Models as icons: Modelling models in the semiotic framework of Peirce's theory of signs. Synthese 190: 3397-3420.

Kress, Gunther; Leeuwen, Theo van 2001. Multimodal Discourse: The Modes and Media of Contemporary Communication. London: Arnold.

Kuhn, Thomas 1970[1962]. The Structure of Scientific Revolutions. (2nd ed.) London: University of Chicago Press.

Kull, Kalevi 1998a. Semiotic ecology: Different natures in the semiosphere. Sign Systems Studies 26(1): 344-371.

- 1998b. Organism as a self-reading text: Anticipation and semiosis. International Journal of Computing Anticipatory Systems 1: 93-104.

- 2003. Ladder, tree, web: The ages of biological understanding. Sign Systems Studies 31(2): 589-603.

- 2009. Biosemiotics: To know, what life knows. Cybernetics and Human Knowing 16(3/4): 81-88.

- 2015. Semiosis stems from logical incompatibility in organic nature: Why biophysics does not see meaning, while biosemiotics does. Progress in Biophysics and Molecular Biology 119(3): 616-621.

- 2018. Choosing and learning: Semiosis means choice. Sign Systems Studies 46(4): 452-466. 
Lakoff, George 1987. Women, Fire, and Dangerous Things: What Categories Reveal about the Mind. Chicago: The University of Chicago Press.

Lavrenova, Olga 2019. Spaces and Meanings: Semantics of the Cultural Landscape. Cham: Springer.

Lestel, Dominique 2011[2002]. The biosemiotics and phylogenesis of culture. In: Maran, Timo; Martinelli, Dario; Turovski, Aleksei (eds.), Readings in Zoosemiotics. Berlin: De Gruyter Mouton, 377-409.

Levesque, Simon 2016. Two versions of ecosophy: Arne Næss, Félix Guattari, and their connection with semiotics. Sign Systems Studies 44(4): 511-541.

Lotman, Juri M. 1977. Primary and secondary communication-modeling systems. In: Lucid, Daniel Peri (ed.), Soviet Semiotics: An Anthology. Baltimore: Johns Hopkins University Press, 95-98.

- 1990. Universe of the Mind: A Semiotic Theory of Culture. London: Tauris.

- 2009[1992]. Culture and Explosion. (Clark, Wilma, trans.; Grishakova, Marina, ed.) Berlin: De Gruyter Mouton.

Lyotard, Jean-François 1984[1979]. The Postmodern Condition: A Report on Knowledge. [La Condition Postmoderne: Rapport Sure le Savoir.] (Bennington, Geoff; Massumi, Brian, trans.) Manchester: Manchester University Press.

MacLarnon, Ann 2012. The anatomical and physiological basis of human speech production: Adaptations and exaptations. In: Tallerman, Maggie; Gibson, Kathleen R. (eds.), The Oxford Handbook of Language Evolution. Oxford: Oxford University Press, 224-235.

Maran, Timo 2010. An ecosemiotic approach to nature writing. PAN: Philosophy Activism Nature 7: 79-87.

- 2014a. Biosemiotic criticism: Modelling the environment in literature. Green Letters: Studies in Ecocriticism 18(3): 297-311.

- 2014b. Biosemiotic criticism. In: Garrard, Greg (ed.), The Oxford Handbook of Ecocriticism. Oxford: Oxford University Press, 260-275.

Maran, Timo; Kull, Kalevi 2014. Ecosemiotics: Main principles and current developments. Geografiska Annaler, Series B: Human Geography 96(1): 41-50.

Marrone, Gianfranco 2017. Farewell to representation: Text and society. In: Bankov, Kristian; Cobley, Paul (eds.), Semiotics and Its Masters. (Semiotics, Communication and Cognition 18.) Berlin: De Gruyter Mouton, 105-119.

Martinelli, Dario 2010. A Critical Companion to Zoosemiotics: Peoples, Paths, Ideas. (Biosemiotics 5.) Dordrecht: Springer.

Martinet, André 1962. A Functional View of Language. Oxford: Oxford University Press.

Næss, Arne 1988. Deep ecology and ultimate premises. Ecologist 18(4/5): 128-131.

Nöth, Winfried 1998. Ecosemiotics. Sign Systems Studies 26: 332-343.

- 2018. The semiotics of models. Sign Systems Studies 46(1): 7-43.

Olteanu, Alin 2015. Philosophy of Education in the Semiotics of Charles Peirce: A Cosmology of Learning and Loving. Oxford: Peter Lang.

Olteanu, Alin; Stables, Andrew 2018. Learning and adaptation from a semiotic perspective. Sign Systems Studies 46(4): 409-434.

Opsahl, Tore; Agneessens, Filip; Skvoretz, John 2010. Node centrality in weighted networks: Generalizing degree and shortest paths. Social Networks 32: 245-251.

Pajević, Marko 2014. Translation and poetic thinking. German Life and Letters 67(1): 6-21. 
Pikkarainen, Eetu 2018. Adaptation, learning, Bildung: Discussion with edu- and biosemiotics. Sign Systems Studies 46(4): 435-451.

Randviir, Anti; Cobley, Paul 2010. Sociosemiotics. In: Cobley, Paul (ed.), The Routledge Companion to Semiotics. New York: Routledge, 118-134.

Rorty, Richard, M. (ed.) 1967. The Linguistic Turn: Essays in Philosophical Method with Two Retrospective Essays. Chicago: University of Chicago Press.

Rockström, Johan; Steffen, Will; Noone, Kevin; Persson, Åsa; Chapin III, F. Stuart; Lambin, Eric F.; Lenton, Timothy M.; Scheffer, Marten; Folke, Carl; Schellnhuber, Hans Joachim; Nykvist, Björn; Wit, Cynthia A. de; Hughes, Terry; Leeuw, Sander van der; Rodhe, Henning; Sörlin, Sverker; Snyder, Peter K.; Costanza, Robert; Svedin, Uno; Falkenmark, Malin; Karlberg, Louise; Corell, Robert W.; Fabry, Victoria J.; Hansen, James; Walker, Brian; Liverman, Diana; Richardson, Katherine; Crutzen, Paul; Foley, Jonathan A. 2009. A safe operating space for humanity. Nature 461: 472-475.

Saussure, Ferdinand de 1959[1916]. Course in General Linguistics. [Cours de linguistique générale.] (Bally, Charles; Sechehaye, Albert, eds.; Baskin, Wade, trans.) New York: McGraw-Hill Book Company.

Schilhab, Theresa; Stjernfelt, Frederik; Deacon, Terrence (eds.) 2012. The Symbolic Species Evolved. (Biosemiotics 6.) Dordrecht: Springer.

Sebeok, Thomas 1991. A Sign is Just a Sign: Advances in Semiotics. Bloomington: Indiana University Press.

- 2001[1994]. Signs: An Introduction to Semiotics. Toronto: University of Toronto Press.

Sebeok, Thomas; Danesi, Marcel 2000. The Forms of Meaning: Modelling Systems Theory and Semiotic Analysis. Berlin: Mouton de Gruyter.

Sharov, Alexei; Maran, Timo; Tønnessen, Morten 2015. Organisms reshape sign relations. Biosemiotics 8(3): 361-365.

Sörlin, Sverker 2012. Environmental humanities: Why should biologists interested in the environment take the humanities seriously? BioScience 62(9): 788-789.

Stables, Andrew 2006. Sign(al)s: Living and learning as semiotic engagement. Journal of Curriculum Studies 38(4): 373-387.

- 2012. Be(com)ing Human: Semiosis and the Myth of Reason. Rotterdam: Sense Publishers.

Stables, Andrew; Bishop, Keith 2001. Weak and strong conceptions of environmental literacy: Implications for environmental education. Environmental Education Research 7(1): 89-97.

Stables, Andrew; Nöth, Winfried; Olteanu, Alin; Pesce, Sébastien; Pikkarainen, Eetu 2018. Semiotic Theory of Learning: New Perspectives in the Philosophy of Education. London: Routledge.

Steffen, Will; Richardson, Katherine; Rockström, Johan; Cornell, Sarah E.; Fetzer, Ingo; Bennett, Elena M.; Biggs, Reinette; Carpenter, Stephen R.; Vries, Wim de; Wit, Cynthia A. de; Folke, Carl; Gerten, Dieter; Heinke, Jens; Mace, Georgina M.; Persson, Linn M.; Ramanathan, Veerabhadran; Reyers, Belinda; Sörlin, Sverker 2015. Planetary boundaries: Guiding human development on a changing planet. Science 347(6223): 1259855.

Stjernfelt, Frederik 2007. Diagrammatology: An Investigation on the Borderlines of Phenomenology, Ontology and Semiotics. Dordrecht: Springer.

- 2011. Signs conveying information: On the range of Peirce's notion of propositions: Dicisigns. International Journal of Signs and Semiotic Systems 1(2): 40-52.

- 2014. Natural Propositions: The Actuality of Peirce's Doctrine of Dicisigns. Boston: Docent Press. 
- 2015a. Dicisign: Peirce's semiotic doctrine of propositions. Synthese 192: 1019-1054.

- 2015b. Iconicity of logic - and the roots of the iconicity concept. In: Hiraga, Masako K.; Herlofsky, William J.; Shinohara, Kazuko; Akita, Kimi (eds.), Iconicity: East Meets West. Amsterdam: John Benjamins, 35-53.

Stuart, Allan 2011. Introduction: Science journalism in a digital age. Journalism 12(7): 771-777. Uexküll, Jakob von 1926. Theoretical Biology. London: Kegan Paul, Trench, Trubner \& Co.

- 1982[1940]. The theory of meaning. (Uexküll, Thure von, ed.) Semiotica 42(1): 1-87.

- 2010[1934, 1940]. A Foray into the Worlds of Animals and Humans with a Theory of Meaning. Minneapolis: University of Minnesota Press.

Vernadsky, Vladimir I. 2005[1943]. Some words about the noösphere. 21st Century Science \& Technology (Spring): 16-21.

Wee, Lionel; Goh, Robbie B. H. 2020. Language, Space and Cultural Play: Theorising Affect in the Semiotics Landscape. Cambridge: Cambridge University Press.

Yang, Zhao; Algesheimer, Rene; Essone, Claudio J. 2016. A comparative analysis of community detection algorithms on artificial networks. Scientific Reports 6: 30750.

\section{Пример семиотического метода в науке о системе Земли: семантические сети экологических исследований}

В статье задается рамка для использования семиотики в качестве аналитического метода для науки о системе Земли. Использование такого метода иллюстрируется путем анализа набора данных (состоящего из 32383 резюме исследовательских статей, относящихся к науке о системе Земли), смоделированного как семантические сети. Анализ позволяет объяснить эпистемологические преимущества этого метода, как исходящие из систем мышления, общих как для науки о системе Земли, так и для семиотики. Цель данного методологического предложения состоит в том, чтобы привлечь внимание экосемиотиков и биосемиотической критики к недавним и критическим рамкам планетарных границ, а также наоборот. Экосемиотика является ветвью теории биосемиотического моделирования и, таким образом, основана на семиотике Чарльза Пирса, но также разработана в духе системной семиотики Юрия Лотмана. Обе эти основы экосемиотики хорошо вписываются в обоснование науки о системе Земли, учитывая схематизм семиотики Пирса и представления Лотмана о значении как данности биосферы. Далеко не исчерпывая герменевтические возможности, вызванные обсуждаемым набором данных, мы утверждаем, что такой семиотический анализ, который стал возможным благодаря возможностям моделирования больших объемов данных, открывает новые горизонты для семиотического анализа, особенно в отношении моделирования окружающей среды. 


\section{Semiootilise meetodi toetuseks Maa süsteemi teaduses: keskkonnauuringute semantilised võrgustikud}

Artikkel pakub välja raami semiootika kasutamiseks Maa süsteemi teaduse analüütilise meetodina. Sellise meetodi kasutamist illustreeritakse, analüüsides 32383 Maa süsteemi teadusega seotud teadusartikli abstraktidest koosnevat andmekogu, mida modelleeritakse semantiliste võrgustikena. Analüüs võimaldab selgitada selle meetodi epistemolooglisi eeliseid, mis tulenevad nii Maa süsteemi teaduses kui ka semiootikas levinud süsteemimõtlemisest. Selle metodoloogilise ettepaneku eesmärgiks on juhtida ökosemiootilise ja biosemiootilise kriitika tähelepanu viimase aja kriitilisele planetaarsete piiride raamistikule ning vastupidi. Ökosemiootika on osa biosemiootilisest modelleerimisteooriast ning tugineb seega Charles Peirce'i skemaatilisele semiootikale, ent on saanud arenemisel inspiratsiooni ka Juri Lotmani süsteemsest semiootikast. Ökosemiootika mõlemad alused sobivad hästi Maa süsteemi teaduse põhjendustega, võttes arvesse Peirce’i semiootika skemaatilisust ning Lotmani tähenduse kui biosfääris esineva võimalduse mõistet. Ammendamata käsitletava andmekogu hermeneutlisi võimalusi väidame me, et selline semiootiline analüüs, mille muudab võimalikuks digitaalne suutlikkus modelleerida suuri andmehulkasid, toob esile semiootilise analüüsi uued horisondid, eriti keskkonna modelleerimise osas inimeste poolt. 